\title{
CPR IN TERMS OF MARITIME SEARCH AND RESCUE SERVICE WORKING CONDITIONS
}

\author{
Roch Jakub Pakula', Szymon Wanat ${ }^{2}$ \\ ${ }^{1}$ Senior Medical Student, Medical University of Silesia, Poland \\ ${ }^{2}$ Polish Maritime Search And Rescue Service, Poland
}

Disaster Emerg Med J 2017; 2(2): 104-105

\section{Dear Editor,}

I am writing to enquire about other readers' opinion regarding a case I have been trying to solve recently.

As an American Heart Association BLS provider and instructor, I had the honor to work with the Polish Marine Search And Rescue Service. We have discussed a scenario concerning a victim being pulled out of the water with sudden cardiac arrest and needing cardiopulmonary resuscitation.

In such a case, we have two strategies to choose from. One is to start CPR in the water, while second is to get to the shore in the shortest possible time and start high quality CPR there. Each of those strategies has pros and cons.

For the first tactic, although the biggest advantage is starting CPR as fast as it is possible, at the same time, due especially in difficult weather conditions such as rough seas we are unable to transport the victim to the shore in a fast and safe way. Moreover, in storm conditions, we are unable to provide high quality CPR. In some extreme storm conditions (Fig. 1) rescuers fight just to stay on board, or even alive, while and any medical procedures, including CPR seem to be impossible and dangerous for them to carry out. Here the question arises of when chest compression becomes completely ineffective and only prolongs the evacuation time of the victim.

The second tactic is to secure the victim on board the lifeboat, reach the shore as fast as possible and start CPR later, but with higher quality, including the usage of AED (Automated External Defibrillator).

As we all know, the guidelines [1] instruct one to start CPR after recognition of cardiac arrest as soon as possible, which points to the superiority of the first tactic. However, while we know that AED usage should be provided as soon an possible, and may not be possible in the case of the aforementioned bad weather conditions, this indicates second tactic to be superior.

Although we have also considered usage of mechanical chest compression devices, which could help to combine both strategies, there is no device declared to be waterproof which seems to be a big problem. Another problem may be the construction of the device itself, which upon application, significantly raises the centre of gravity of the victim, exposing them to falling out of the boat.
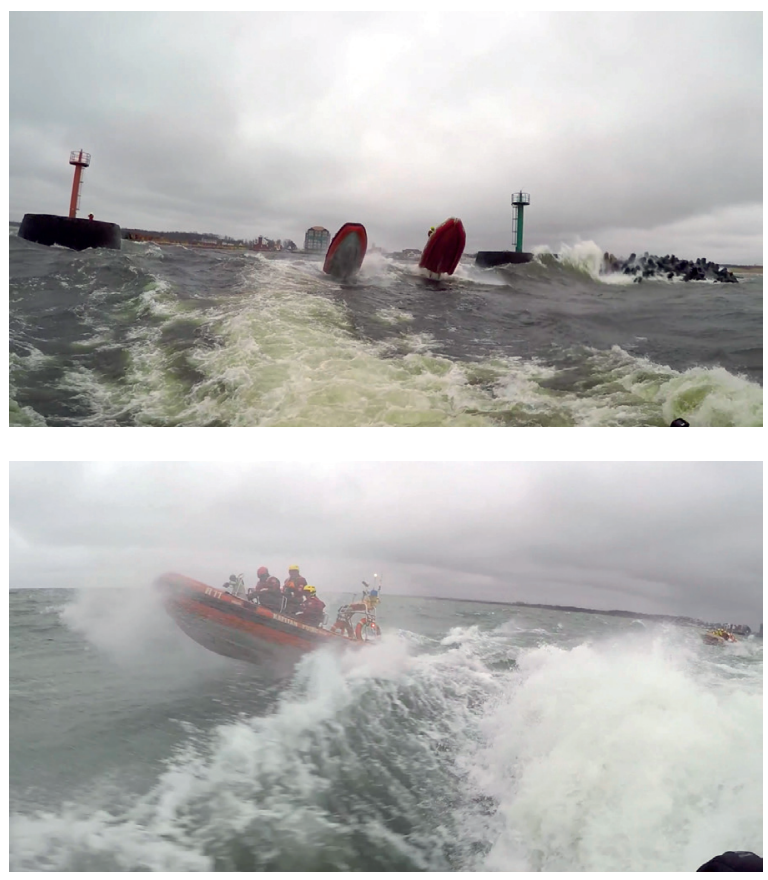

FIGURE 1. Examples of storm working conditions 
In real life situations, it is always harder to make a decision, especially when we realize we do not have any cut-off point between these methods as not everything is just black or white and often face complex problems which seem to be shades of gray.

Polish Maritime Search And Rescue Service rescuers are constantly practicing such manoeuvres gaining invaluable experience.

We are planning a study including a comparison of the quality of chest compression and mechanical chest compression device usage in different con- ditions such as lifeboat speed, rough seas, wind speed, etc. This should help one to find the best answer to this difficult question, as well as choose the best way to provide life-saving treatment.

Conflict of interest: None declared.

\section{REFERENCES}

1. Neumar R, Shuster M, Callaway C, et al. Part 1: Executive Summary. Circulation. 2015; 132(18 suppl 2): S315-S367, doi: 10.1161/cir.0000000000000252. 